\title{
Flight of ideas - death of a definition: a discussion on phenomenology
}

\author{
Neil Jeyasingam ${ }^{1}$
}

The Psychiatrist (2013), 37, 359-362, doi: 10.1192/pb.bp.111.036194

${ }^{1}$ Hornsby Hospital, Sydney, Australia First received 18 Jul 2011, final revision 21 Apr 2013, accepted 29 Apr 2013 Correspondence to Neil Jeyasingam (njeyasingam@nsccahs.health.nsw. gov.au)
Summary Phenomenology provides the foundations on which the functions of modern psychiatry stand. It also provides a common language for the assessment of patients, and for the education of the next generation of psychiatrists. However, phenomenology is not anchored in independent clinicopathological correlates, and therefore it is vulnerable to subtle alterations over time. This article briefly discusses some concepts regarding phenomenology and attempts to comment on the various definitions available under the common descriptor termed 'flight of ideas'. It is asserted that without appropriate monitoring and teaching of these basic descriptors and recognising the value of historical observations, serious inconsistencies will continue to arise in clinical theory and practice, which may prove difficult to rectify.

Declaration of interest None.
Phenomenology is the precise definition of psychiatric symptoms. Nosology is the classification of diseases, using phenomenological descriptors as a base. A diagnosis is formed by using nosology as a guide.

All these three statements carry with them several caveats. However, they also form a generalised description of the art of psychiatric diagnosis. Few would disagree that modern psychiatry is firmly founded on phenomenology, which acts both as a common language and a means for psychiatric assessment, treatment, research and education. However, phenomenology itself is not invulnerable. There have been both subtle and serious changes in the way it is viewed, taught and practised. These changes affect how patients are assessed, and crucially, affect how patients are managed. Without monitoring these changes, towers are built on sand.

\section{Defining (and using) phenomenology}

Derived from the Greek phainómenon meaning 'that which appears', Immanuel Kant contrasted it with 'noumenon', referring to an event which cannot be sensed. ${ }^{1}$ Edmund Husserl, ${ }^{2}$ however, interpreted it in terms of internal subjective experiences - a hybrid of the older concepts of phenomenon and noumenon. The term 'phenomenology' was thus born. Martin Heidegger and Karl Jaspers made it a school of thought dedicated to making the structures of consciousness objects of systematic reflection and analysis, to allow the therapist to understand the world of the patient.

Phenomenology was also meant to be flexible. Jaspers considered it to only attain a 'fixed point of reference when externally validated clinicopathological entities set its boundaries'. ${ }^{3}$ Until that time, psychopathology and phenomenology would remain provisional, and refutable.

As a philosophy, phenomenology works well with many basic sciences that eventually undergo taxonomic classifications based on underlying processes and known origins. However, in psychiatry, major risks arise from definitions produced without precise theoretical underpinning. Definitions can become clouded, or subtly altered, over time. Without constants, diagnoses built on such changed definitions risk becoming shaky and fluid.

A definition is nothing more than a tool. When the tool is changed, it ceases to do what it used to do. As an example, consider the commonplace term of 'flight of ideas'.

\section{Flight of ideas, the first $\mathbf{5 0}$ years}

Kahlbaum, in describing catatonic excitement states in 1874, wrote of 'hystrionic exaltation, expansive mood permeating all speech [with] constant declamations and recitations'. ${ }^{4}$ Some authorities consider these descriptions precursors of descriptions of manic excitement. ${ }^{5}$ The actual term 'flight of ideas', or Ideenflucht, first appeared in the title of the noted neurologist and psychiatrist Liepmann's 1904 work, where he described his many observations of logorrhoea - or 'superrepresentations' ${ }^{6}$

The term is perhaps best known to us today from Bleuler, who in 1923 commented:

"Even normal persons who are "in good humor", or "stimulated" sometimes give the subjective and objective impression as if their thinking process ran with particular ease ... In pathological states ... we often find a morbid exaggeration of the afore-mentioned state, which is designated as flight of ideas. Here the most striking phenomenon is the exaggerated distractability, which at first comes from within but later also from without. The patients change their objective idea with abnormal frequency' (p. 7l). ${ }^{7}$ 
Even in these earliest descriptions, Bleuler attempted a holistic usage of the practice of phenomenology to provide an objective assessment of the observed behaviour as well as to hypothesise the underlying thought process - that of an abnormal increase in changes in objective ideas, with distractibility coming 'from within but later also from without'. More notably, he made a comment regarding the issue of linking flight of ideas to the speed of thought:

'Flight of ideas does not represent a simple acceleration of associations. Liepmann endeavoured to explain it on the basis of a disturbance of attention, but one gains nothing by it as one can just as lief reason the other way and explain disturbances of attention through flight of ideas ... As intrapsychic functions are only too easily stimulated in manic patients . . the stimulus threshold seems smaller and the relation between inhibition and function is disarranged' (pp. 73-74). ${ }^{7}$

It is a concise and elegant description of the processes involved in the described behaviour. It also only discusses mechanisms of associations of thought, which is appropriate as a 'thought form' descriptor. Bleuler went on to comment on its syndrome specificity. In the following quote, he discusses his colleague Kraepelin's observations:

'Whereas the empirically acquired structures of associations are not loosened in flight of ideas and impediment of thought as well as in organic disturbances of associations, their effectiveness is restricted in schizophrenia. Neither a manic patient, nor a sound person thinks of modern Italy at the mention of the name of Brutus. But a schizophrenic, by disregarding the component of time connected with the term, can call the Roman an "Italian"” (p. 77).

Kraepelin also suggests that each of his terms occupies its own domain: 'The chief symptoms usually appearing in the manic phase are: psychomotor excitement with pressure of activity, flight of ideas, distractibility, and happy though unstable emotional attitude' (p. 381). ${ }^{8}$ At this point, 'flight of ideas' was designated to mean an abnormal increase in connections between ideas. Tight connections were still maintained. There was no comment regarding the speed of the patient's speech, which was separately described with appropriate descriptors.

However, approximately 50 years later the speed of the patient's speech started to creep into the definition, as Beck described:

'The spontaneous speech of the patient is usually increased and he generally finds it difficult to stop talking. He may continue to talk or sing until he becomes hoarse or he may lose his voice entirely. He frequently shows a flight of ideas by moving rapidly from one subject to another. In contrast to the disconnected flight of ideas of the schizophrenic, the manic usually demonstrates some unifying theme underlying his tangential associations' (p. 101).

It is unclear what Bleuler would have made of the concept of the 'disconnected flight of ideas of the schizophrenic'. The term 'flight of ideas' at this point appears to have had subdomains within itself, rather than being a single building block for constructing a nosology. Fish's seminal 1974 work on psychopathology aimed to restore the elegance of the original definitions. Starting with an appropriate apology to the science, he asserted:

'Any classification of these disorders is bound to be arbitrary. Thus it has been customary to divide thought disorders into disorders of content and disorders of form [that is] disorders of belief and disorders of reasoning . . . Apart from these two disorders one can talk of disorders of the stream or progress of thought, which is also a somewhat arbitrary concept . . [Disorders of the stream of thought] can be divided further into disorders of tempo and disorders of continuity . . . [In flight of ideas] the thoughts follow each other rapidly, there is no general direction of thinking and the connexions between successive thoughts appear to be due to chance factors which, however, can usually be understood. The patient's speech is easily diverted to external stimuli and by internal superficial associations' (pp. 34-35). ${ }^{10}$

However, at this stage, 'flight of ideas' had started to allow weak linkages between ideas, as Fish wrote:

'The absence of a determining tendency to thinking allows the associations of the train of thought to be determined by chance relationships, verbal associations of all kinds, such as assonance, alliteration, and so on, clang associations, proverbs, old saws, and clichés' (p. 35). ${ }^{10}$

\section{A revision of phenomenology - flight of ideas post-1974}

Another major attempt to try to address these inconsistencies occurred with Andreasen's article in 1979, which had positive intentions:

'Evaluation of the Bleulerian perspective has been severely handicapped by the lack of any standard widely agreed-on definition of thought disorder ... This report presents a set of definitions [that are derived] from clinical experience, use an empirical approach, and avoid making inferences about underlying processes of thought'. ${ }^{11}$

Note the decision to deliberately avoid theoretical supposition in the definitions. Definitions were now written from 'clinical experience', and then evaluated for their interrater reliability. There are important philosophical implications in this, the least of which was that the definition of a 'phenomenon' was now restored to Kantian times, and therefore, a concept of phenomenology that pre-dates Husserl. There were, however, some casualties in this upheaval:

'The present investigation was undertaken to provide a consistent set of definitions that could become standard and could be used with high reliability ... . for example, the term "flight of ideas" has been dropped and is now subsumed under the concepts of derailment and pressure of speech'.11

Thus, the new definition consisted of:

'Derailment (Loose Associations, Flight of Ideas) - A pattern of spontaneous speech in which the ideas slip off the track onto another one that is clearly but obliquely related, or onto one that is completely unrelated ... At times, there may be a vague connection between the ideas; at others, none will be apparent. This pattern of speech is often characterised as sounding "disjointed". Perhaps the commonest manifestation of this disorder is a slow, steady slippage, with no single derailment being particularly severe, so that the speaker gets farther and farther off the track with each derailment without showing any awareness that his reply no longer has any connection with the question that was asked'.

Andreasen provided a contrast to tangentiality as well: 'Flight of ideas is a derailment that occurs rapidly in the context of pressured speech. Tangentiality has been defined herein as a different phenomenon in that it occurs as the immediate response to a question,. ${ }^{11}$ This was provided as a response to how less severe derailments had previously been referred to as either tangentiality or flight of ideas when in the context of mania. Andreasen felt this to be an 
unreliable distinction, and thus provided these new definitions.

There are profound implications in this decision. Mullen discussed how Jasper's contributions were to envisage a nosology that was open ended and evolutionary, as clinical research progressed and, eventually, 'externally validated clinicopathological entities set its boundaries'. ${ }^{12}$ However, instead of the nosology being tackled, the underlying phenomenology instead was changed deliberately in order to avoid inappropriate diagnostic specificity.

Andreasen in 1995 would then discuss flight of ideas as simply being 'a subjective experience of accelerated thought'. ${ }^{13}$ What was once the objective assessment of a pattern of distractibility had now become the subjective experience of faster cognition.

Recent descriptions again varied between the loose associations and pressure of speech descriptors, as in 1997:

'Flight of ideas is encountered in manic ... and it can even appear in relatively pure form in some subjects, who on other criteria would be considered undoubtedly schizophrenic. There is an accelerated tempo of speech often referred to as pressure of talk. In addition to the increased rate of delivery, the language employed is characterised by a wealth of associations, many of which seem to be evoked by more or less accidental connections ... . the excited speech wanders off the point following the arbitrary connections, and the coherent progress of ideas tends to become obscured ... In flight of ideas, a wide range of unusual connections drive on the rapid speech and listener is often borne along by the flow' (p. 38). ${ }^{12}$

If one were to summarise the various definitions, a table might emerge (Table 1).

\section{Clinical relevance}

This should not be considered merely an interesting academic exercise, as phenomenology is integral to how psychiatric diagnoses are made. But assessing the variation brings new questions. Do the changes in definitions actually cause any problems? Surely phenomenology itself should be allowed to evolve, as it is only based on clinical observations in the first place. The concern I would like to raise is that an evolving nosology is easily tracked, as simple as checking the version number of the DSM or ICD manual consulted. However, an evolving phenomenology is much more subtle and leads to significant disparities between assessments from different periods in history.

And indeed, there is empirical evidence of how inconsistent phenomenology has affected diagnoses. For example, a study of how several Amish patients were misdiagnosed as having schizophrenia rather than bipolar disorder noted misdiagnosis often occurred due to inaccurate assessments of thought form. ${ }^{14} \mathrm{~A}$ study of nine patients with thought disorder who were manic at the time of study noted significant 'schizophrenic' symptoms and concluded that there was a need for precise definition and descriptors of thought form, to minimise diagnostic uncertainty. ${ }^{15}$

Consider the case study in Box 1 . It is certainly an isolated case, which had minimal other available collateral information to assist with distinguishing between potential diagnoses. However, it illustrates the problem with drift in a single definition, leading to significant variance in diagnostic formulation, clinical decision-making and patient welfare.

\section{Discussion}

No suggestion should be inferred from any part of this article that criticism is warranted against any of the writers listed. Seminal authorities provided appropriate descriptions, based primarily on clinical impressions gathered at the time the descriptions were provided. But the lengthy apologies that were later made, some even associated with the earliest descriptions, expose the shifting nature of these terms.

The earliest definitions by psychiatry's forefathers were tightly integrated with appropriate descriptions of thought patterns and conscious experiences, so as to create an objective set of data that could be collated and then collectively analysed to create meaningful diagnoses. As demonstrated, this ethos has changed.

Granted, it can be argued that meaning is retained even with a changing phenomenology. Jaspers envisioned a phenomenology that evolved and was provisional. But it is difficult to consider the above as a mere evolution when there is such disparity between the meanings of the same phrase. Andreasen noted a lapse in appropriate teaching of careful clinical evaluation and knowledge of psychopathology, ${ }^{5}$ brought on by DSM's superior authority in diagnosis. If so, it is ironic that 'flight of ideas' is in the DSM criteria for a manic episode. Note must additionally be made of Andreasen's observation that the psychoanalytic movement led to a de-emphasis on observed signs and symptoms: 'In fact, the psychoanalysts taught that the patient's self-report of both symptoms and other internal experiences should be discounted. The analyst must dig beneath self-report to reach the real truth'. ${ }^{16}$

However, many changes in the definition pre-date the DSM system of classification. It is possible that the previous criticisms of the 'authoritative' nosology validate the

\begin{tabular}{lllll}
\hline \multicolumn{2}{l}{ Table $\mathbf{1}$} & 'Flight of ideas' - variations in the definition by time & & \\
Year & Writer & Linkages between ideas & Speed of thought & Syndrome specificity \\
\hline 1923 & Bleuler, Kraepelin & Increased, normal connections & No comment & Manic \\
\hline 1972 & Beck & Disconnected & Increased speed & Schizophrenia \\
\hline 1974 & Fish & Weak linkages & No comment & No comment \\
\hline 1979 & Andreasen & Weak linkages & Increased speed & Not specific \\
\hline 1995 & Andreasen & No comment & Increased speed & No comment \\
\hline
\end{tabular}




\section{Box 1}

\section{Case study}

The impetus for this article arose from my experience in being involved with the care of a 72-year-old nursing home resident. Her documentation for the preceding 15 years consisted of a diagnosis of schizophrenia with moderate cognitive impairment, with intermittent exacerbations characterised by worsened thought form, increased agitation, increased paranoia and poorer sleep, although her baseline was not far from these exacerbations. Managed mostly with risperidone (save two admissions where olanzapine was trialled with similar responses), her treatment history consisted of approximately once-yearly admissions with short-term increases in her antipsychotic regime, a partial amelioration of symptoms and being returned to the nursing home. What was notable, however, was her mental state examination - although there was no pressure of speech, her thought form resembled the earlier Bleulerian flight of ideas, but not later definitions. Assuming a Bleulerian flight of ideas definition, she would meet DSM-IV criteria for a manic episode, but not otherwise.

She was given a trial of sodium valproate in conjunction with her pre-existing risperidone. Within 1 week, there was a marked improvement in her sleep, and in the following weeks a total resolution of thought form disorder and all other aberrant behaviours, with her concentration and appetite also improving. She even became less dependent on her walking frame due to her improved nutrition and physical health. She eventually returned to her nursing home to far superior functioning, to the point that she started escorting other residents to social events. To my knowledge she has not since had a mental health readmission.

acceleration of the deterioration in phenomenology, but what is more apparent is the subtle way in which time shifts one's understanding of terminology. It is attrition, rather than an evolution. Perhaps what is necessary is something similar to Andreasen's 1979 work, but rather than describing a set of phenomenology that shows good interrater reliability, it may assess phenomenology based on diagnostic validity. This perhaps will provide the necessary grounding until objective clinicopathological correlates arise. Until then, definitions will continue to meander.

And if the definitions are no longer the same definitions that they used to be, then there is less and less possibility for coherent meaning. An inconsistent phenomenology leads to serious repercussions, in the common language of psychiatrists and in the use of the terms in psychiatric assessment, treatment, education and research. Eventually, one reaches a state when two clinicians may assess a patient, and arise at separate conclusions. Without monitoring the foundations, it will be impossible to tell where the division occurred.

\section{Acknowledgements}

Many thanks for the helpful comments of Tim Lambert, Philip Tam, P. Jeyasingam, and to the many reviewers for their valuable insights and contributions to the development of this article.

\section{About the author}

Neil Jeyasingam is Clinical Associate Lecturer, Sydney University, and Staff Specialist Psychogeriatrician, Northern Sydney Area Health Service, Australia.

\section{References}

1 Kant I (1781) Critique of Pure Reason. Dover Philosophical Classics, 2003

2 Husserl E. Ideas: General Introduction to Pure Phenomenology (trans. WR Boyce Gibson). George Allen \& Unwin, 1931.

3 Mullen P. A modest proposal for another phenomenological approach to psychopathology. Schizophr Bull 2007; 33: 113-21.

4 Kahlbaum KL. Catatonia (trans. Y Levi, T Pridon T). The Johns Hopkins University Press, 1973

5 Taylor MA, Fink M. Catatonia in psychiatric classification: a home of its own. Am J Psychiatry 2003; 160: 1233-41.

6 Liepmann H. Über Ideenflucht: Begriffsbestimmung und psychologische Analyse [About Flight of Ideas: Definition and Psychological Analysis]. Carl Marhold, 1904.

7 Bleuler E. Textbook of Psychiatry (trans. AA Brill). George Allen \& Unwin, 1923.

8 Diefendorf AR, Kraepelin E. Clinical Psychiatry: A Textbook for Students and Physicians (abstracted and adapted from the 7th German edition of Kraepelin's Lehrbuch der Psychiatrie): pp. 381-422. MacMillan Co, 1923.

9 Beck A. Depression. University of Pennsylvania Press, 1972.

10 Hamilton M (ed.) Fish's Clinical Psychopathology, Signs and Symptoms in Psychiatry. John Wright \& Sons, 1974.

11 Andreasen N. Thought, language and communication disorders 1. Clinical assessment, definition of terms, and evaluation of their reliability. Arch Gen Psychiatry 1979; 36: 1315-21.

12 Mullen P. The mental states and states of mind. In The Essentials of Postgraduate Psychiatry (eds R Murray, PD Hill, P McGuffin): 3-40. Cambridge University Press, 1997.

13 Andreasen N. Introductory Textbook of Psychiatry. Donald Black, American Psychiatric Publishing, 1995.

14 Egeland JA, Hostetter AM, Eshleman 3rd SK. Amish Study, III: the impact of cultural factors on diagnosis of bipolar illness. Am J Psychiatry 1983; 140: 67-71.

15 Jampala VC, Taylor MA, Abrams R. The diagnostic implications of formal thought disorder in mania and schizophrenia: a reassessment. Am J Psychiatry 1989; 146: 459-63.

16 Andreasen NC. DSM and the death of phenomenology in America: an example of unintended consequences. Schizophr Bull 2007; 33: 108-12. 